\title{
A Successful Seeded Fault Engine Test to Detect Cracks in Engine Disks (TF-41 SFET) ${ }^{1}$
}

\author{
William Emmerling \\ Don Altobelli \\ FAA William J. Hughes Technical Center \\ Atlantic City International Airport, New Jersey 08405 \\ Dave Lewicki \\ U.S. Army Research Laboratory \\ NASA Glenn Research Center at Lewis Field \\ 21000 Brookpark Road, Mail Stop 23-3 \\ Cleveland, Ohio 44135 \\ Chuck Frankenberger \\ Silvia Seng \\ Naval Air Warfare Center, Weapons Division \\ 1 Administration Circle \\ China Lake, CA 93555-6100 \\ Leo Fila \\ Naval Air Systems Command \\ 22195 Elmer Rd. \\ Patuxent River, MD 20670
}

Abstract-Turbine engine disk failure, although rare, is a
leading propulsion related safety hazard in aviation. Fan
disk failures in particular pose a threat due to the size and
number of fragments liberated during the failure. This
effort seeks to develop a proactive means to detect an
impending failure condition and remove the engine from
service prior to failure. The FAA,US Navy, US Air Force,
and NASA have teamed up, in what could be considered a
model application of collaboration, to explore and
develop various technologies that show promise in
detecting cracks in disks real time while on board an
aircraft. These four agencies have combined funds and
effort to set up a test in which the first stage fan disk of a
TF- 41 engine was seeded with an Electrical Discharge
Machining (EDM) notch and the disk was then subject to
Low Cycle Fatigue loading to propagate the crack until
burst. This paper will detail from a government
perspective the intricacies of coordinating not only
between many different government agencies, but with
the seven different businesses that participated in the
program to test and further develop their technologies.
An explanation of this test will be given along with all
that went into planning for the test and the making of key
decisions. Some of the hurdles that will be discussed are:
selecting where to place the EDM notch, size of the EDM
and

${ }^{1}$ U.S. Government work not protected by U.S. copyright. notch, how to mount the different sensors onto the engine in a non-intrusive manner, and how to develop an engine cycle that could accommodate all participants' requirements while still ensure disk rupture at approximately a predetermined time.

\section{TABLE OF CONTENTS}

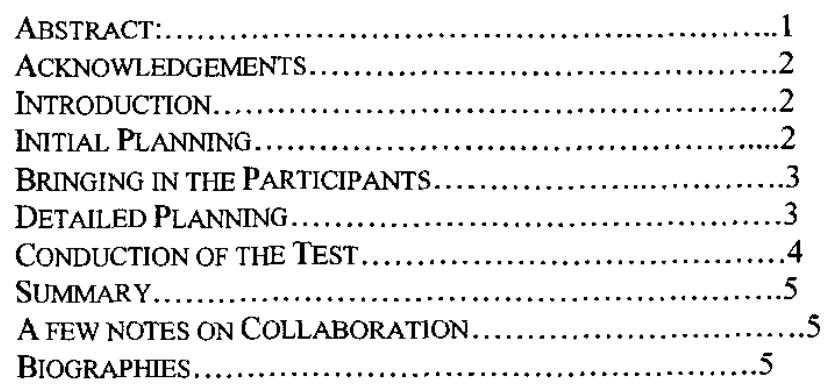

\section{ACKNOWLEDGEMENTS}

The conduction of this test could not have been carried out without the hard work and selflessness of all the participants, both on the government side as well as the contractor side. 


\section{Vol. 7-3028}

One person who certainly deserves special recognition for his support of the test is Mr. Bill Hertz of Spectrum Inc. FMS group at the Lake Gray office in Jacksonville Florida. Mr. Hertz is an ex-TF-41 maintainer and currently works as a support contractor for the Jacksonville Naval Depot. $\mathrm{He}$ was instrumental in securing for us much needed test instrumentation and equipment, including the disk that was used, as well as general expertise on the operation of the engine. For this, we would like to thank him profusely and acknowledge that we couldn't have done it without him.

\section{INTRODUCTION}

In June of 2001, the FAA Tech Center, Atlantic City, NJ contacted Naval Air Systems Command, Patuxent River, MD about the possibility of running a test in which a technology could be tested that they believed had the ability to detect cracks in engine disks while the engine was running. The plan was to run the engine under low cycle fatigue conditions until disk burst, effectively destroying the engine. The Navy had testing facilities at the Naval Air Systems Command, Weapons Division base at China Lake, California who were then brought into the test planning. Regular conference calls were held in the early stages of planning to determine what the best approach would be to carry out the test.

Many of the companies that participated in this test have also submitted papers for the IEEE 2003 Aerospace Conference. This paper is by no means an attempt to explain in detail all the techniques and results obtained from running this test. This paperis solely to describe the government perspective of coordinating and running a test of this sort. More detailed information regarding the techniques used to detect the disk crack can be obtained from reading the papers of those that chose to submit them, or by contacting directly the companies which participated.

\section{InItial Planning}

During the first stages of planning, it was decided that as long as a single engine was going to be run to failure, it would be best to piggy back as many different candidate technologies so as not to have anyone miss out on the opportunity. Up until this time, the majority of the work on real time disk crack detection has been in single stage spin pit facilities, or in a few cases, a multi stage stack in a spin pit. The FAA and US Navy felt that having a full engine test would give all participants a full set of data with all the inherent background vibrations and background "noise" that goes with it. With this data, the participants could then better tune their methods with the overall goal of someday boarding the technology on an actual flying aircraft.

There were a few initial decisions that had to be made that would then set the tone for the rest of the planning. These included what type of engine to use, what stage to target, where on the disk should the EDM flaw be inserted, and approximately how many cycles we would like to run the test for. As it turned out, choosing the flaw location became one of the more important decisions and was deferred to the detailed planning stage. Also, the very important decision of who to invite to the test needed to be made. These decisions were handled via telecons held early in the planning period.

Upon discussing the engine type to choose, we quickly decided that the list of candidate engines was quite small. The engine we chose would have to be one in which all necessary parts could be obtained, a candidate engine could be secured to run the test, and most importantly the asset could not be needed elsewhere as the conclusion of the test would render the engine out of commission. Candidates included the F-100, F-110, F-404 and TF-41 engines. Upon further discussions, it was determined that the only engine for which we had all necessary resources, as well as spare engines that would no longer be missed in the fleet was the TF-41 engine (Fig. 1). China Lake was already in possession of two TF-41 engines, and the Naval Depot, Jacksonville, FL had the spare disks, equipment and tooling that was needed to operate the engine. Once the engine was selected, the next step was to determine

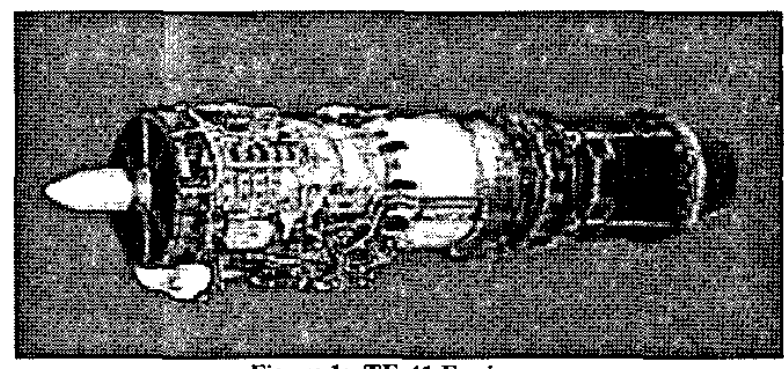

Figure 1: TF-41 Engine

which stage should be targeted for flaw insertion. Since the TF-41 engine has a 3 stage fan, 2 stages of intermediate compression, and an 11 stage compressor, this was not a trivial task. Considerations were made with respect to accessibility, stresses involved, locations for installing instrumentation and sensors, as well as ease of conducting inspections during the test. With all those things in mind, the First Stage of the Fan was selected to insert the flaw into because of the ease of assembling the flawed disk onto the test stand as well as the ability to access the first stage more easily than the other stages.

The government participants discussed the possible locations of the crack, and quickly decided that for the money at stake, it was best to conduct a stress analysis of the disk to determine the optimal locations, therefore postponing this decision for several months.

Upon performing a search of potential solutions to the problem of disk crack detection, the US Navy sent out a request for quotes to all potential participants. After weighing the potential candidates with the funding requests and available funding, the following candidates were selected: 
Innovative Dynamics of New York for a technique that involves applying a wire mesh to the disk. When a crack traverses the sensor, the mesh is broken and a signal is sent to alert the users that there is a crack.

Allison Advanced Development Corporation for a method that involves acoustic measurement sensors. When a crack is present and growing, the theory is that the sound emitted can be captured and characterized by the sensing system.

ExSell Incorporated for work involving tip timing probes and a change in center of mass of a disk in the presence of a crack.

Hood Technology for a technique involving tip timing probes that can detect shifts in blade tips in the presence of a crack.

Creative Engineering for a method that seeks to detect and classify changes in torsional vibration of the shaft with the cracked disk.

In addition, it was found tat the following companies were also pursuing disk crack detection technologies under existing government contracts:

Test Devices Inc was selected under funding from a US Air Force Phase II SBIR for a method involving a combination of tip timing probes and vibration measurements.

General Electric Aircraft Engines was selected under funding from NASA Glenn for a method involving vibration methods.

Because of this, the US Air Force and NASA were then brought into the consortium along with the FAA, US Navy Patuxent River, and the US Navy China Lake. It should be noted that the USAF and NASA were involved in all aspects of planning the test.

\section{BRINGING IN THE PARTICIPANTS}

Once the participants were selected, the decision had to be made of how to contract with so many different companies utilizing multiple funding sources. Test Devices Inc. and GE Aircraft Engines were both funded by the USAF and NASA respectively under their existing contracts. Hood Technology already had an existing SBIR contract with the US Navy Patuxent River, and that contract was exploited to get funding for Hood Tech.

That left 4 companies without existing contracts that could be utilized. Since the funding for these four companies was to come from a mixture of Navy Pax funds and FAA Funds, it was decided to combine the funds into a single pool and fund the companies from that.
The Navy, Pax River was responsible for this contracting process.

Right around this time, November of 2001, all government participants had their first face to face meeting at the FAA Regional office in Boston MA. At this meeting, we discussed the current status of the testing, the funding process, financial situation, and ways to proceed with the test. This meeting came 5 months after the FAA first contacted the Navy, and after all initial planning of the testing had been agreed upon.

At the same time, the FAA also sent funding to the US Navy China Lake for the actual setting up and running of the engines.

\section{Detalled Planning}

During the time that we were getting all participants on contract, China Lake was working closely with Test Devices Inc. to find a way to instrument the engine with all necessary sensors in order to run the test. Test Devices was chosen to design and manufacture an instrumentation ring that was then welded on the engine inside the first stage fan (Fig. 2). Test Devices was selected for two reasons: First, because their previous extensive experience with the TF-41 engine gave them knowledge and insight that the majority of the other contractors didn't have: and second, their contract with the USAF had provisions for developing this instrumentation ring, so the work was already paid for. This ring not only incorporated Test Devices Inc. Sensors, but also sensors from some of the other participants.

The time frame for which all of this was accomplished gave way to another face to face meeting in May of 2002 at China Lake. There were multiple purposes of this meeting. First and foremost was to set up and run the TF-41 to ensure it was still in working condition. In addition, we installed the instrumentation ring on the engine, and ran several cycles of baseline data so that the participants could have an example of an unflawed engine to compare against. The government also wanted to have meetings with all participants to ensure we had their requirements understood and that they were still in a position to attend the test. Finally, we needed to discuss further the location of the flaw as the preliminary results of the stress analysis were being made available.

The engine on the test stand was in proper working order during the week for which we targeted. Consequently, we were successfully able to run various cycles for those companies that were hoping to obtain baseline data. The format for the meeting was to be two days. The first day was to get everybody involved in the test in the same room and have a discussion of what needed to be done and what would be the best way to proceed. The second day was set aside to give each individual company an opportunity to speak directly to the government about their particular method and any special requests they had. This was done in an effort to protect any proprietary information that may have been discussed. As it turned out, none of the companies chose to take advantage of the second day's schedule. Consequently, 
the meeting turned into a two day open forum for the discussion of the test which proved to be extremely beneficial.

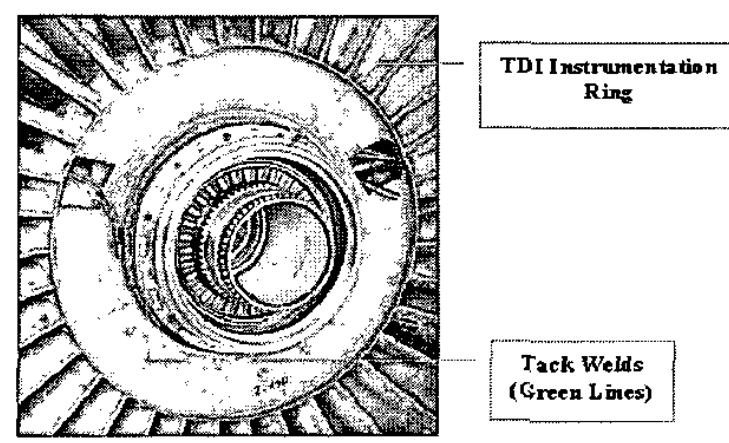

Figure 2: Instrumentation Ring

One of the first items for discussion was to determine the location of the seeded flaw. The decision was made considering input from all the contractors on where they felt would be a good candidate as well as the results of the analysis conducted by Impact Technology (Fig. 3). It was determined that the front face of the disk, approximately half way between the bore and the dovetail slot should be the location of the flaw. Due to monetary concerns, it was also determined that the number of cycles we hoped to run prior to burst would be somewhere between 1,500 $-3,000$. We wanted enough cycles so that each company could track growth of the crack, but no so many cycles that it tapped our financial resources. The stress analysis dictated a flaw size of 5 thousandths of an inch wide with a 100 thousands of an inch radius to meet our objectives.

Additional requirements of the suppliers were also discussed. However, since most of the companies requiring sensor data already had their sensors mounted on the engine to collect baseline data, there were very little requests of the government.

Due to the unpredictable nature of cracks in disks, it was determined that it would not be a good idea to go from inserting the EDM notch directly to the engine. Therefore, we made the decision to place the flawed disk into a spin pit facility at Test Devices Inc. and conduct cycling until crack initiation. Once the crack was initiated, the disk would then be shipped to China Lake for insertion into the engine and run to failure.

Because of the sensitive nature of collecting baseline data and the minute changes in baseline data to that of flawed data, the question of how to conduct inspections of the crack during the test is not a trivial one. History in spin pit testing shows us that something as simple as removing and replacing a blade can alter the signal in such a way as to lose continuity between runs, thereby increasing the challenge of detecting and tracking a crack. However, if no inspections were performed, how would we know if a crack was present, and if it was progressing as the analysis predicted? In the end, we decided that there would be no tear downs to inspect the crack so as to keep the data as normalized as possible. We will, however, use a specially machined nose bullet with a hole drilled in it as a means of possibly inspecting the disk without taking apart any of the engine. The hole will allow for someone to visually inspect the crack or possibly use a borescope tool to inspect the crack.

\section{CONDUCTION OF THE TEST}

It was planned at the time of abstract submittal for this conference that the TF-41 test would be run in September of 2002. Unfortunately, as the old adage goes, no plan survives execution, and this plan was no exception. At the time of writing this paper, the TF-41 disk has exceeded the preallotted number of cycles in the Test Devices Spin Pit. They have currently paused spinning of the disk awaiting the delivery of further funding for that purpose. Cycling of the disk should commence approximately the second week of November, and upon successful crack initiation the next planned time at the China Lake test stand is in Mid-January of 2003. Results from each of the vendors are expected to be in approximately 6 weeks after the test comes to completion.

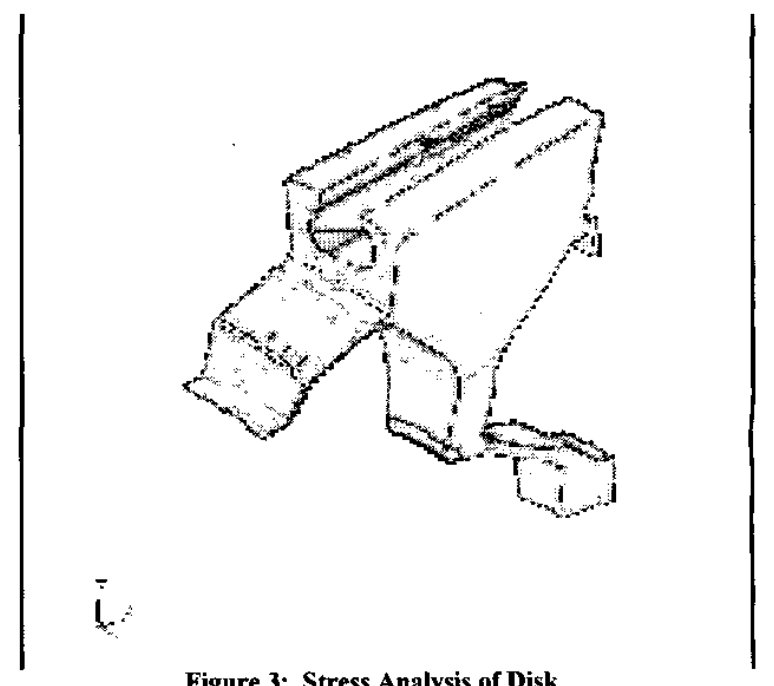

Figure 3: Stress Analysis of Disk

The current plan is for the actual engine test to take no more than 2 weeks and 1,500 to 3,000 cycles as was previously mentioned. One cycle of the engine is defined as a ramp up from 2,800 RPM to 8,500 RPM, dwell time at 8,500, ramp down from 8,500 to 2,800 RPM and an additional dwell at 2,800 RPM, and will take approximately 3 minutes. In addition, as per a request from one of the participants, every $50^{\text {th }}$ cycle will consist of a longer dwell time at the high RPM in order to collect a better sampling of data.

\section{SUMMARY}

A successful completion of the test will be marked by a disk burst. It is unclear at this point how well any or all of the participants will be able to detect the crack. The purpose of 
this test is to perform risk reduction efforts and to provide an opportunity for the many companies currently developing disk crack detection techniques with the overall goal of showing success with one or more technique.

Follow on efforts are in the preliminary planning stages at this point in time. It is believed that all participating government agencies will continue on in their efforts to develop a technology that can detect disk cracks real time-on board an aircraft. The current plan is to take all technologies that have promising results out of this engine test and further develop them until the conduction of a similar engine test sometime in the early 2004 time frame.

Working on a collaborative program such as this has truly been a rewarding experience. Because of the nature of the program, all four participating government agencies were able to bring a relatively small amount of money to the table and get a large amount of R\&D in return. Furthermore, an integral development effort of this sort eliminates the stove piped efforts in which each agency attempts to find a particular solution alone, and in the end much money is wasted with little to show. By initiating this collaboration, each agency has visibility into what the others are doing, and all have been able to leverage off of multiple funding sources.

The program management has been one of a consortium, with each person always keeping in mind the final goal of successfully running an engine test with as many technologies as is practical. Despite a few planning periods in which regular telecons were made and two face to face meetings between participants, most of the communication took place through e-mail and with individual phone calls between parties. The key to the successes that we've had so far has been strong communication and a desire to see the test succeed.

\section{A FEW NOTES ABOUT COLLABORATION}

Collaboration is an excellent way to stretch budgets that have already been stretched, and are continuing to dwindle with present day cuts. The authors firmly believe that, if done correctly, there is no reason why a collaborative effort cannot be successful in reaching its goals.

The effort described above was done with only a single written agreement between the US Navy and the FAA. The biggest hurdle to overcome when attempting a collaborative effort is not having written agreements, but having trust and communication between the participants. It is important that everybody involved has a clear understanding of what their role is, and that everybody sticks to their roles. Of course, the clear objectives must be stated and understood by all participants in order to keep everybody focused on the common goals of the program and to avoid somebody working against the common good.

\section{BlographiES}

Mr. Leo Fila graduated from Virginia Tech with a Dual Major in Aerospace Engineering and Ocean Engineering. Upon Graduation, he worked as a support contractor in the Joint Strike Fighter Program Office. In June of 2001, he became employed by the US Naval Air Systems Command. He still works in the propulsion IPT of the JSF Program office, but also serves as the engine controls and diagnostics S\&T development lead at Patuxent River Naval Air Station.

Mr. William Emmerling P.E. is a general engineer for the Federal Aviation Administration where he is a research program manager of the Aircraft Catastrophic Failure Prevention Program. Research under the program develops data and analysis to support rulemaking related to uncontained engine failures and propulsion malfunctions. He graduated from Villanova University with a Bachelors Mechanical Engineering and was inducted into $\mathrm{Pi}$ Tau Sigma. $\mathrm{He}$ holds a professional engineering license in the state of Pennsylvania. His previous employers were the Naval Air Propulsion Center and Westinghouse Electric Corporation Combustion Turbine Systems Division.

Mr. Don Altobelli received a BSME from Newark College of Engineering. He joined the Naval Air Propulsion Center in 1974 as a project engineer in the small turbine engine test group. In 1983, he became the center's Program Manager for Drive Systems. After transferring to NAWC-AD-Pax in 1993, he became the Technical Lead for Auxiliary Power Systems. He moved to the FAA in 1999. His current role is the Research Position Description Manager for the Aircraft Catastrophic Failure Prevention Program at the FAA William J. Hughes Technical Center. The prime objective of this Program is to prevent / mitigate uncontained engine failures by supporting research. His responsibilities are to manage and direct research efforts in this area.

Dr. David G. Lewicki is employed by the U.S. Army Research Laboratory's Vehicle Technology Directorate at the NASA Glenn Research Center at Lewis Field in Cleveland, Ohio. He has been performing analytical and experimental research in transmission, gearing, and bearing areas for rotorcraft and turboprop drive train applications since 1982. He has been involved in gear crack propagation research, as well as transmission life and reliability predictions and gear dynamics predictions. He has performed various transmission and related component experiments, and has been involved in programs such as low-noise, high-strength spiral-bevel gears, face-gears for helicopter drive systems, lubricants, and diagnostics. Dr. Lewicki has earned a Ph.D. from Case Western Reserve University, a M.S.M.E. degree from the University of Toledo, and a B.S.M.E. from Cleveland State University. He has authored/co-authored over 80 technical publications to date in the drive system area. $\mathrm{He}$ is also a member of the American Society of Mechanical Engineers and is a previous Associate 
Technical Editor for power transmission and gearing for the Journal of Mechanical Design.

Mr. Chuck Frankenberger is a graduate of the University of Arizona. He currently works in the Systems Vulnerability Branch of the Naval Air Warfare Center, Weapons Division, China Lake, CA. He is involved in working vulnerability issues for the Joint Strike Fighter Program.

Mrs. Silvia Seng Silvia Seng is a graduate of Texas A\&M University, with a B.S. in Aerospace Engineering. She is employed in the Systems Vulnerability Branch, located at Naval Air Warfare Center Weapons Division, China Lake. Her current position focus is Aircraft Engine Survivability. 